\title{
Concrete, Reinforced By Carbon Fibre Composite Structure, Load Bearing Capacity During Cracking
}

\author{
Krishna Kiran Annamaneni \\ Ecological Construction Engineering \\ Centre, Institute of Building \\ production, \\ Riga Technical University \\ Riga, Latvia \\ kk.annamaneni@gmail.com
}

\author{
Bhumika Vallabhbhai Dobariya \\ Ecological Construction Engineering \\ Centre, Institute of Building \\ production, \\ Riga Technical University \\ Riga, Latvia \\ bhumikapatel1515@gmail.com
}

\author{
Andrejs Krasnikovs \\ Department of Theoretical \\ Mechanics and Strength of Material \\ Riga Technical University \\ Riga, Latvia \\ Andrejs.Krasnikovs@rtu.lv
}

\begin{abstract}
Different authors conducted studies on fiber reinforced concretes (FRC) with carbon fibres of different lengths and some results showed that concrete mix with homogeneously distributed short fibres in their volume have good strength and ultra-strain compared to normal plain concrete mix. However, this study is focused more on 3dimensional (3D) carbon fibre reinforced plastic (epoxy) CFRP composite thin rods frame used as a reinforcement in concrete which shows good increase in loadbearing and ductility. Were investigated concrete mixes with superplasticizer, nano-silica, quartz sand, fine natural sand and gravels. Diagonal cross bracing carbon fibre epoxy frames were used as a reinforcement giving better ductility results. Proposed study approach is to show that the reinforced concrete with provided materials have an increased performance in terms of ductility, sustainability, and load bearing in cracked statement. Total, four groups of concrete and each group with three beams were casted and tested in this experiment, three groups with three different shapes of carbon frames and three beams without frames to compare the mechanical properties after 28 days. Failure mechanisms in any particular case were analysed.
\end{abstract}

Keywords - carbon fiber, composite rods frame, concrete, bending, deflection, ductility.

\section{INTRODUCTION}

The most used material in the construction sector is concrete. Despite the centuries-old experience of using concrete, its composition is constantly being improved and optimized depending on the purpose and tasks [1]. Back in the days of the Roman Empire, concrete made a real revolution in construction [2], [3]. Since then, concrete has been reinforced in various ways and materials, for example: bars made of different materials [4]-[7], different short fibres [8]-[10], and using different technologies [11]-[14]. The addition of discrete fibers to the concrete mixture to enhance its toughness and tensile strength is well acknowledged. Studies have also shown that fiberreinforced concrete (FRC) [15] can be favorable for its enhanced behavior in tension and compression [16]. This behavior, which is attributed to the confinement action of the fibers, is, in general, superior in terms of strength and ductility, compared to plain concrete [17]. Fibers act as the reinforcement and bridge the gaps and micro - cracks within concrete, resulting in the high strength and energy absorption capacity of fiber - reinforced concrete [18], [19].

Short fibres in the specimens are randomly distributed across the volume. Short fibre-reinforced concrete is a homogeneous material. But saying "homogeneous" it doesn't means homogeneous in reality, because during filling the construction formwork and mix flowing process, fibres added to the concrete mix blend are obtaining nonhomogeneous distribution and orientations in the fresh mix concrete volume which inevitably affects the mechanical properties of FRC [20]-[24]. In the same time, the reinforcement with rods provides for their guaranteed, local 2D or 3D arrangement. Here we want to accent thin rods instead thick rebars. Modern fibers (Carbon, Boron, etc.) can have high elastic modulus (few times higher 
comparing with steel) and high strength. Preparing thin rods 3D frames will allow to create densely reinforced

Carbon fiber reinforced polymers (CFRP) are innovative composite materials that have been applied for repairing and retrofitting civil engineering structures. CFRP can not only be used as a strengthening material for the reinforced concrete (RC), but also can play a protective coating layer role [25]. Carbon fiber reinforced concrete (CFRC) have more advantages regarding the properties compared to the concrete without any fibers in it [26]. Coming to the $3 \mathrm{D}$ fiber polymer matrix reinforcing frame in the concrete, there are many advantages of this combination, the frame placement and orientation in the concrete remarkably affects its load carrying, strength, cracking and energy absorption performance. It was identified that the concrete reinforced by multi axis 3D composite fiber structure has strain hardening behavior. The strain hardening increased the energy absorbing capacity of the reinforced concrete [27]. Fibers yarns impregnated by epoxy resin are forming composite rods in 3D frames providing stiffness and strength [28].

Present research assumes the use of custom-made carbon fiber rods frames in concrete with their 3D orientation.

\section{MATERILAS AND METHODS}

\subsection{Concrete mix materials}

In the current research the following components were used for FRC mix materials:

1. Cement- CEM I 52.5 N, Ordinary Portland Cement (OPC);

2. Fine Sand, Quartz sand - 0-1 mm and Quartz powder 0-120 mk were used for the concrete mix;

3. Sikament ${ }^{\circledR} 56$ - superplasticizer was used to provide mix flow ability and good dispersion of microparticles. Basic properties: light yellow and easy flowable

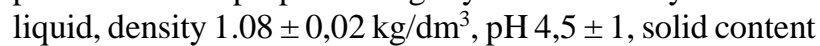
$37 \pm 1 \%$. (Recommended dosage: in the range $0.1-2.0 \%$ by weight of cement).

\subsection{Fibres}

Carbon fibers were used in this research (Table 1). In the plywood plate were screwed in few screws. Around these screws were stretched carbon fiber string, forming different structures (see Fig. 1a-c). Stretched string between fixed screws was impregnated by epoxy resin. After epoxy matrix solidification carbon fiber composite frame is becoming stiff. Frames were taken away and were used as reinforcement in the concrete prisms. Three frames (groups) with different geometry were fabricated, box (rectangle shape) frame was named as the group $1, \mathrm{~V}$ shape bracing was named as the group 2 and the cross bracing was named as the group 3. No reinforcement/frame was named as the group 4 (Fig. 1a1c \& Table 2).
TABLE 1 PROPERTIES OF CARBON FIBER

\begin{tabular}{|l|c|}
\hline Diameter, $\mathrm{mm}$ & 2 \\
\hline Density, $\mathrm{kg} / \mathrm{m}^{3}$ & 1820 \\
\hline Tensile strength, GPa & 7.06 \\
\hline Modulus of elasticity, GPa & 441 \\
\hline
\end{tabular}

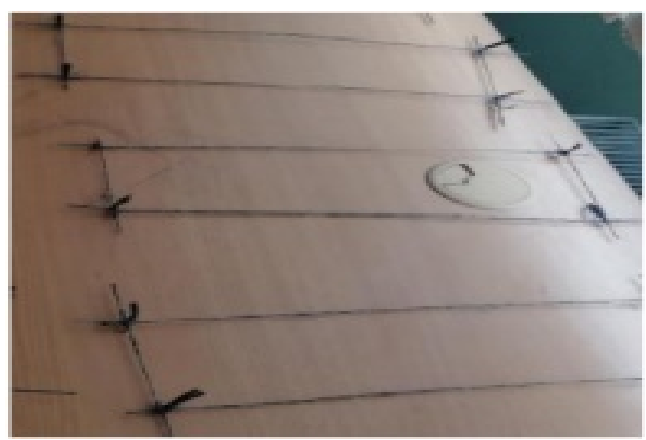

Fig.1a Box frame

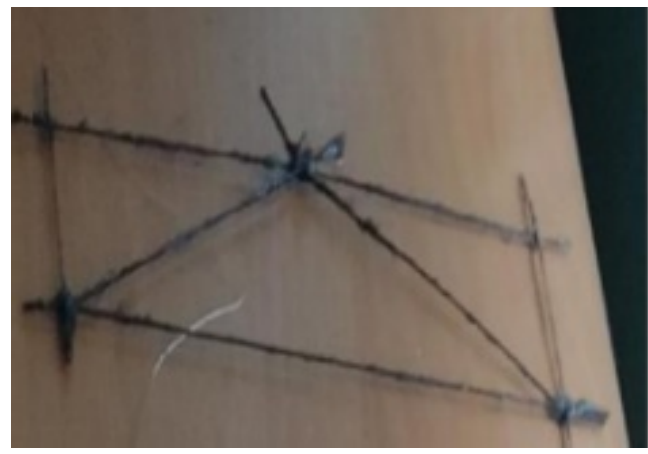

Fig.1b V frame

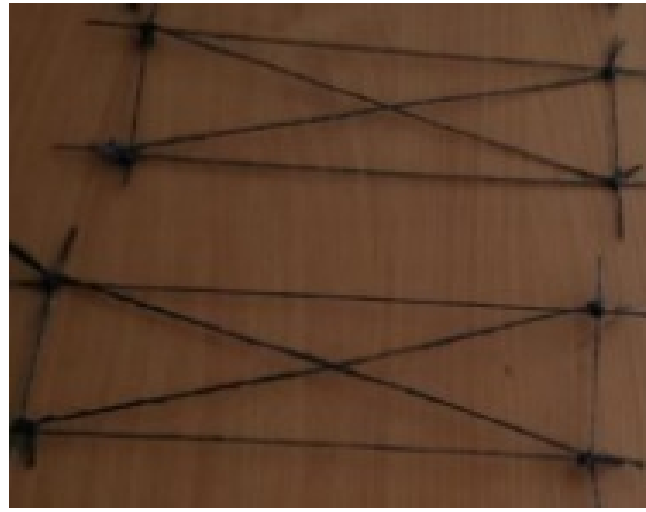

Fig.1c Cross frame

TABLE 2 REINFORCEMENT SHAPE AND GROUPING

\begin{tabular}{|c|c|}
\hline Group No. & $\begin{array}{c}\text { Reinforcement type/Shape of } \\
\text { frame }\end{array}$ \\
\hline Group 1 & Box frame \\
\hline Group 2 & V shaped frame \\
\hline Group 3 & Cross frame \\
\hline Group 4 & No reinforcement \\
\hline
\end{tabular}

2.3 Concrete mix design: The water to cement ratio was $\mathrm{W} / \mathrm{C}=0.75$ in each group and the amounts of 
Environment. Technology. Resources. Rezekne, Latvia Proceedings of the $13^{\text {th }}$ International Scientific and Practical Conference. Volume 2, 232-238

ingredients are tabulated for $1 \mathrm{~m}^{3}$ of volume of concrete as per the table 3 .

TABLE 3 MIX PROPORTION

\begin{tabular}{|l|c|}
\hline \multicolumn{1}{|c|}{ Vol of Concrete } & $\mathbf{1 ~ m}^{\mathbf{3}}$ \\
\hline Cement Content $(\mathrm{kg})$ & 400 \\
\hline Water Content $(\mathrm{kg})$ & 300 \\
\hline Fine Sand $(\mathrm{kg})$ & 1400 \\
\hline Superplastcizer $(\mathrm{kg})$ & 3 \\
\hline Quartz Powder $(\mathrm{kg})$ & 250 \\
\hline
\end{tabular}

\subsection{Samples preparation:}

\subsubsection{Concrete mixing:}

The concrete mix was prepared according to the design to maintain the workability [29] of concrete. Fibre frames were placed at the centre of the mould by filling the bottom part first with the concrete layer $2 \mathrm{~cm}$ thick, placing the frame carefully and filling the remaining part till the concrete layer thickness rich $8 \mathrm{~cm}$. Then the second frame was placed and after that concrete was filled till the top of the mould providing the required strength to the specimen (see Figure 2). By this two fiber frame, the risk of fibers orientation and stress concentration [30] at one place in the sample can be avoided and the stress will be equally distributed. We have a total of four groups of FRC with three fabricated beams per each group, making it twelve beams in total.

Three groups with the carbon fibre frames and the fourth group without any fiber frame in it.

\subsubsection{Sample sizes}

The FRC was placed into the prism's moulds of size $100 \times 100 \times 400 \mathrm{~mm}$. All groups were casted as per the code provisions, placed for the curing [31] in water and tests were done for 28 days.

\section{EXPERIMENTAL TESTS AND RESULTS}

\subsection{Tests for Structural properties}

\subsubsection{Compressive strength testing procedure of concrete cubes}

In concrete design and quality control, compressive strength is the property generally specified and by which concrete is classified. Compressive Testing Procedure and strength of concrete cube the defining strength properties of these materials, be detected both by non-destructive methods [32]-[34] and by the classical destructive method in accordance with EN 12390-3. Standard compressive cube tests using $100 \times 100 \times 100 \mathrm{~mm}$ specimens were conducted to determine of the concrete compression strength without any fibers in the concrete including three specimen's data after 28 days. The compressive strength for the concrete is $24.91 \mathrm{~N} / \mathrm{mm}^{2}$. According to the EN 206 is corresponds to the concrete strength class C16/20.

\subsubsection{Four Point Bending Test (4PBT)}

The 4PBT is traditionally used to find out the flexural strength of the concrete specimen. In the used test for FRC mechanical and fracture properties determination test is carrying in a mode of crack propagation during bending. We used 4PBT as a test with constant bending moment in a sample, placed between the two upper supports as shown in fig. 2. We have several standards, such as EN 14651, ASTM C1018-97, ASTM C 1399, ASTM C 1609, DAfStb-Richtlinie: Stahlfaserbeton, DVB Merkblatt Stahlfaserbeton, and RILEM TC 162-TDF for this test to obtain the results as per the standards. Testing is carried as per those standards and results were noted.

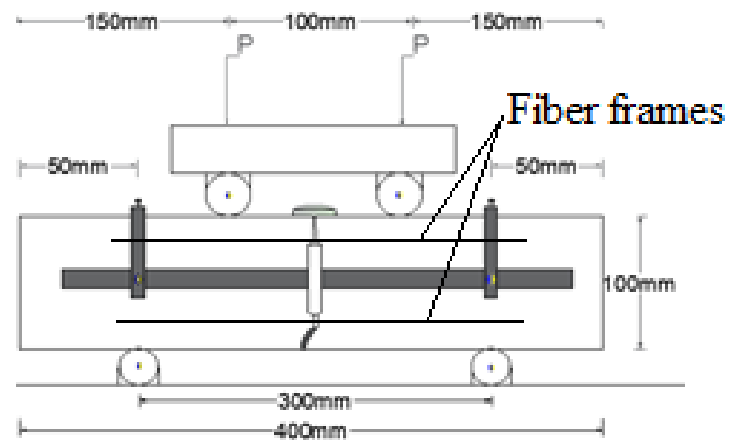

Fig. 2 Four Point Bending Test scheme

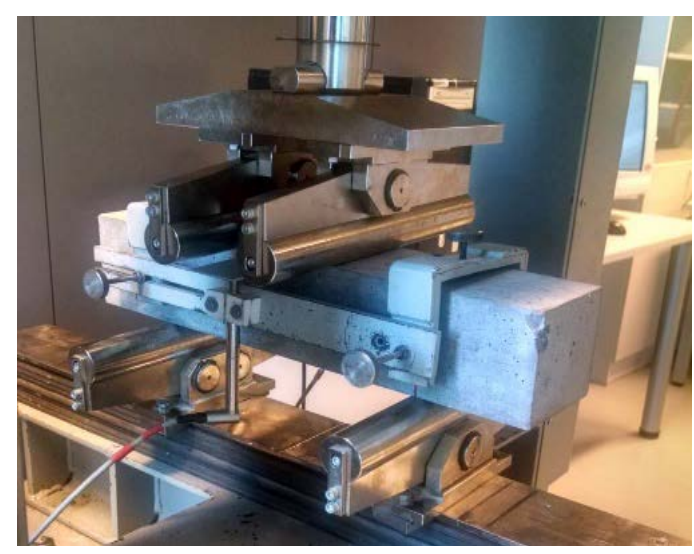

Fig. 3 Testing of FRC beams

\subsubsection{PBT Testing Procedure:}

The four groups of FRC, were experimentally tested by placing them as shown in the scheme (fig. 2) according to the markings made on them as per the load points. Later, the frame with two HBM WA20 LVDTs sensors on its sides used for recording deflection of the beam during the test were placed on the same marks. Mechanical properties verification was carried out by 4PBT method using Controls Automax 5 loading machine. Load was applied in 0.25 $\mathrm{kN}$ steps for the span of 60 seconds.

The loading was applied monotonically in small increments, while the load and deflection were 
recorded at each increment. The midspan vertical deflection was measured with LVDT. The load versus vertical deflection (of the middle of a span) curve was obtained in every loading. The measurement data from the strength measurements by using HBM Spider-8 data acquisition system was processed, synchronised, and saved in MS Excel files which later were used to form the required graphs. Deflection of the beam was obtained by considering and summing the values from both sides sensors and the average value was calculated for every loading step in every experiment. The graphs showing the processes in FRC, were created from these files with MS Excel.

The test procedure was carried out for all the four groups in the same manner as shown in the fig. 3 and the graphs were plotted. Loads were applied until the every beam fails and breaks completely.

\subsection{Four Point Bending Tests graphs}

\section{Group 1- Group 4 4PBT average results}

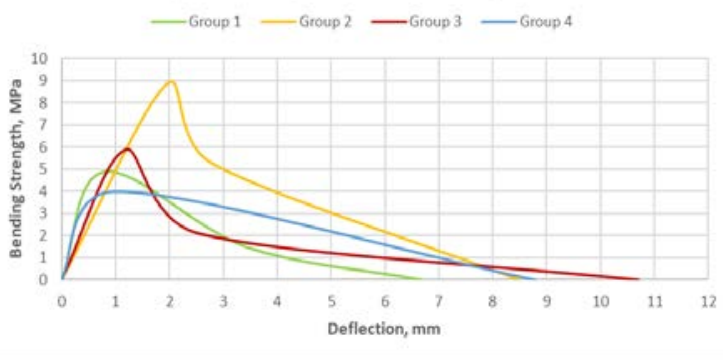

Fig. 4 Average graphs: Stress-middle of a span Deflection, for all groups

All values were taken for four groups, strengthdeflection average values were plotted using the $M A T L A B$ software for the 4PBT test and based on them, the average graphs were drawn for all the groups. In majority of the performed tests, one single crack was formed on the bottom part of the beam during its bending until rupture. Performed by different authors geometrical evaluations shown that in this case middle point vertical deflection is equal to crack mouth opening displacement (CMOD).

Discussing obtained data is possible to note:

Group 1:

1. This frame is very easy to make but these samples show lowest maximal bending strength. This group has the maximal bending strength of 4.90 $\mathrm{MPa}$ with maximal midpoint deflection (CMOD) of $6.70 \mathrm{~mm}$ (fig. 4). Then beam failed. Only two composite sticks reinforced bottom part of the beam. Reinforcement raptured by carbon fibers failure and pulling out of the fibers tails from the polymer matrix.
Group 2:

1. The group has the highest bending strength of 8.89 $\mathrm{MPa}$, which is almost double the strength of the group 1 with the maximal deflection (CMOD) of $8.49 \mathrm{~mm}$.

2. This frame is not as easy to make as the group 1 . Due to the joints on one of its sides, this group looks different.

Group 3:

1. The group with the good performance in terms of deflection, which is $10.70 \mathrm{~mm}$, better than all the groups. We can suppose that in this case single fiber failure inside the sticks happened at bigger length (pulled out tails were longer). Nevertheless, it needs additional experimental investigation.

2. Bending strength of this group is $5.90 \mathrm{MPa}$, which is less than the group 2 but higher than in the group 1 and 4.

Group 4:

1. This group have the bending strength of $5.53 \mathrm{MPa}$, greater than group 1 and near to group 3 . Deflection of this group is $8.79 \mathrm{~mm}$.

Along with these, some more observations can also be made,

a. Concrete beams with these kinds of reinforcements (framed) will have the fibers positioned well compared to beams with short fibers thrown into the concrete mix.

b. Results scatter is smaller.

c. There will be no wastage like breaking/damaging of fibers while mixing the concrete.

d. Fiber frames can be placed exactly in the necessary location inside the beams what is not possible to make with the short fibers.

e. Since the reinforcement is a single member, the elongation of the fibers will be more compared to the each individual fiber.

\section{CONCLUSIONS}

The following conclusions can be made from the above results:

1. The group 2 is the strongest of all with the highest bending strength. This helps the structures to bear the loads acting on it and provides the strength required but the deflection is not as expected.

2. The frame made in the group 1 can be labelled as the weakest group among the first three groups as the Bending strength is less compared to all the other groups. It can also be said that it is still better than the group without any kind of fiber frames in it. 
3. For the group 3, the connections between its corners made it to perform well regarding the deflection. The centre of frame made it so as the diagonals meet each other at the centre and thereby increasing its elongation strength.

4. The group 4, with no kind of fiber frame in it have the better deflection than the group 1 and almost similar to group 2.

5. Geometry of the concrete mix member must be taken care while adding the frame type reinforcement.

6. It was obtained that the compressive strength of concrete cubes with fibers is more than the cubes without fibers.

\section{REFERENCES}

[1] G. Sahmenko et al., "The study of the combined effect of fly ash, silica fume, colloidal silica and superplasticizer on high performance cement composite applying mix optimization method,” Mech. Compos. Mater., 2021.

[2] C. J. Brandon, R. L. Hohlfelder, M. D. Jackson, and J. P. Oleson, Building for Eternity: The History and Technology of Roman Concrete Engineering in the Sea. Oxford: Oxbow Books, 2014

[3] P. F. Brune, A. R. Ingraffea, M. D. Jackson, and R. Perucchio, "The fracture toughness of an Imperial Roman mortar," Eng. Fract. Mech., vol. 102, pp. 65-76, Apr. 2013.

[4] V. L. Kulakov, G. P. Terrasi, A. K. Arnautov, G. G. Portnov, and A. O. Kovalov, "Fastening of a High-Strength Composite Rod with a Splitted and Wedged End in a Potted Anchor 2. FiniteElement Analysis,” Mech. Compos. Mater., vol. 50, no. 1, pp. 3950, Mar. 2014.

[5] A. Kovalovs, P. Akishin, and A. Chate, "Detection Prestress Loss in Prestressed Concrete Slab using Modal Analysis,” IOP Conf. Ser. Mater. Sci. Eng., vol. 471, p. 102015, Feb. 2019.

[6] S. Ramanathan, V. Benzecry, P. Suraneni, and A. Nanni, "Condition assessment of concrete and glass fiber reinforced polymer (GFRP) rebar after 18 years of service life,” Case Stud. Constr. Mater., vol. 14, p. e00494, Jun. 2021.

[7] A. Kovalovs, S. Rucevskis, P. Akishin, and J. Kolupajevs, "Numerical Investigation on Detection of Prestress Losses in a Prestressed Concrete Slab by Modal Analysis,” IOP Conf. Ser. Mater. Sci. Eng., vol. 251, p. 012090, Oct. 2017.

[8] I. Lasenko, S. Gaidukovs, and J. Rombovska, "Manufacturing of amber particles suitable for composite fibre melt spinning,” Proc. Latv. Acad. Sci. Sect. B Nat. Exact, Appl. Sci., vol. 70, no. 2, pp. 51-57, 2016.

[9] A. Macanovskis, A. Lukasenoks, A. Krasnikovs, R. Stonys, and V. Lusis, "Composite Fibers in Concretes with Various Strengths,” ACI Mater. J., vol. 115, no. 5, Sep. 2018.

[10] S. Gaidukovs, I. Lyashenko, J. Rombovska, and G. Gaidukova, "Application of amber filler for production of novel polyamide composite fiber,” Text. Res. J., vol. 86, no. 20, pp. 2127-2139, Dec. 2016.

[11] V. Lusis et al., "Effect of short fibers orientation on mechanical properties of composite material-fiber reinforced concrete," J. Civ. Eng. Manag., vol. 23, no. 8, pp. 1091-1099, Nov. 2017.

[12] O. Kononova, A. Krasnikovs, G. Harjkova, and V. Lusis, "Numerical simulation of mechanical properties for composite reinforced by knitted fabric,” in Ebook Congreso Mundial, 2014, vol. 5, pp. 2925-2932.

[13] A. Krasnikovs, O. Kononova, A. Machanovskis, V. Zaharevskis, P. Akishins, and S. Ruchevskis, "Characterization of mechanical properties by inverse technique for composite reinforced by knitted fabric. Part 2. Experimental evaluation of mechanical properties by frequency eigenvalues method," J. Vibroengineering, 2012.
[14] V. Lusis and A. Krasnikovs, "Fiberconcrete with NonHomogeneous Fibers Distribution,” Environ. Technol. Resour. Proc. Int. Sci. Pract. Conf., vol. 2, p. 67, Aug. 2013.

[15] P. Zhang, S. Han, S. Ng, and X. H. Wang, "Fiber-Reinforced Concrete with Application in Civil Engineering,” Adv. Civ. Eng., vol. 2018, 2018.

[16] O. Kononova, V. Lusis, A. Galushchak, A. Krasnikovs, and A. Macanovskis, "Numerical modeling of fiber pull-out micromechanics in concrete matrix composites," J. Vibroengineering, vol. 14, no. 4, pp. 1852-1861, 2012.

[17] R. Eid and P. Paultre, "Influence of synthetic fibers on the seismic behavior of reinforced-concrete circular columns,” vol. 228, no. February 2020, 2021.

[18] H. M. Abdulaziz Alaskar, Abdulrahman Albidah, Ali Saeed Alqarni, Rayed Alyousef, "Performance evaluation of high strength concrete reinforced with basalt fibers exposed to elevated temperatures.,” 2021, vol. 35, no. December 2020.

[19] A. Macanovskis, A. Krasnikovs, O. Kononova, and A. Lukasenoks, "Mechanical Behavior of Polymeric Synthetic Fiber in the Concrete,” Procedia Eng., vol. 172, pp. 673-680, 2017.

[20] H. Herrmann, O. Goidyk, and A. Braunbrück, "Influence of the Flow of Self-Compacting Steel Fiber Reinforced Concrete on the Fiber Orientations, a Report on Work in Progress,” in Part of the Advanced Structured Materials book series (STRUCTMAT, volume 95), Springer, Cham, 2019, pp. 97-110.

[21] H. Herrmann, O. Goidyk, H. Naar, T. Tuisk, and A. Braunbrück, "The influence of fibre orientation in self-compacting concrete on 4-point bending strength,” Proc. Est. Acad. Sci., vol. 68, no. 3, p. 337, 2019.

[22] A. Krasnikovs, V. Zaharevskis, O. Kononova, V. Lusis, A. Galushchak, and E. Zaleskis, "Fiber Concrete Properties Control by Fibers Motion Investigation in Fresh Concrete During Casting,” in 8th Int. DAAAM Balt. Conf. "INDUSTRIAL Eng., 2012, pp. 657-662.

[23] C. Bao, J. H. Bi, D. Xu, J. Guan, and W. X. Cheng, "Numerical simulation of the distribution and orientation of steel fibres in SCC,” Mag. Concr. Res., vol. 72, no. 21, pp. 1102-1111, Nov. 2020.

[24] H. Herrmann, A. Braunbrück, T. Tuisk, O. Goidyk, and H. Naar, "An Initial Report on the Effect of the Fiber Orientation on the Fracture Behavior of Steel Fiber Reinforced Self-Compacting Concrete,” in Advanced Structured Materials, 2019, pp. 33-50.

[25] A. Wei, R. Al-ameri, Y. C. Koay, and M. Y. J. Tan, “Triplefunctional carbon fibre reinforced polymer for strengthening and protecting reinforced concrete structures,” vol. 24, no. January, 2021.

[26] Z. Wang, G. Ma, Z. Ma, and Y. Zhang, "Flexural behavior of carbon fiber-reinforced concrete beams under impact loading," Cem. Concr. Compos., vol. 118, no. January, 2021.

[27] K. Bilisik and H. Ozdemir, "Multiaxis three dimensional ( 3D ) carbon and basalt preforms / cementitious matrix concretes : Experimental study on fiber orientation and placement by panel test,” Constr. Build. Mater., vol. 271, p. 121863, 2021.

[28] L. Yang, P. Han, and Z. Gu, "Grafting of a novel hyperbranched polymer onto carbon fi ber for interfacial enhancement of carbon fi ber reinforced epoxy composites,” Mater. Des., vol. 200, 2021.

[29] M. Sahmaran, A. Yurtseven, and I. Ozgur Yaman, "Workability of hybrid fiber reinforced self-compacting concrete,” Build. Environ., 2005.

[30] T. Park et al., "Evaluation of orientation and distribution of steel fibers in high-performance concrete column determined via micro-computed tomography,” Constr. Build. Mater., vol. 270, 2021.

[31] A. T. Lee, M. Michel, E. Ferrier, and B. Benmokrane, "Influence of curing conditions on mechanical behaviour of glued joints of carbon fibre-reinforced polymer composite / concrete,” Constr. Build. Mater., vol. 227, 2019. 
Krishna Kiran Annamaneni, et al. Concrete, Reinforced by Carbon Fibre Composite Structure, Load Bearing Capacity

[32] B. Ogunbayo and C. Aigbavboa, "Experimental Investigation of Concrete Block Walls Compressive Strength Using a Nondestructive Test,” 2021, pp. 393-397.

[33] A. Tatarinov, A. Shishkin, and V. Mironovs, "Correlation between ultrasound velocity, density and strength in metalceramic composites with added hollow spheres,” IOP Conf. Ser. Mater. Sci. Eng., vol. 660, p. 012040, Dec. 2019.
[34] V. Mironov, I. Pundiene, A. Tatarinov, and J. Baroninsh, "A Study of Metal-Cement Composites with Additives,” Constr. Sci., vol. 16, no. 1, Jan. 2014. 